\title{
Investigation of Potential Environmental Impacts and Sustainable Management of Municipal Solid Waste using the Driving force-Pressure-State- Impact-Response-Outcome (DPSIRO) framework: Case of Bahir Dar, Ethiopia
}

Awoke Misganaw ( $\sim$ awokemisganaw12@gmail.com )

Debre Tabor University https://orcid.org/0000-0002-9859-0226

\section{Banchamlak Akenaw}

Wolkite University

\section{Research Article}

Keywords: Sustainable management, Eutrophication potential, Greenhouse gas emission, Municipal solid waste, Framework, Ethiopia

Posted Date: December 14th, 2021

DOI: https://doi.org/10.21203/rs.3.rs-1126390/v1

License: (1) This work is licensed under a Creative Commons Attribution 4.0 International License.

Read Full License 
Title: Investigation of potential environmental impacts and sustainable management of

2 municipal solid waste using the Driving force-Pressure-State-Impact-Response-Outcome

3 (DPSIRO) framework: Case of Bahir Dar, Ethiopia

4 Awoke Misganawa,", Banchamlak Akenaw ${ }^{\text {b }}$

$5{ }^{a}$ Faculty of Technology, Department of Chemical Engineering, Debre Tabor University, Debre

6 Tabor, Ethiopia: awokemisganaw12@gmail.com

7 baculty of Technology, Department of Chemical Engineering, Wolkite University, Wolkite,

$8 \quad$ Ethiopia: abesis44@gmail.com

$9 \quad *$ Corresponding author address:

10 Email: awokemisganaw12@gmail.com

11 Mobile: +251-932-852-548

12 Posta 272

13 Abstract

14 The generation of MSW in urban areas in Ethiopia and elsewhere continues to increase and

15 poses a challenge to city governments and citizens if the wastes are not properly managed.

16 Applying an integrated system for managing MSW and recovering the material for use in new

17 products can reduce the negative impacts on the environment. The purpose of this study is to

18 apply the DPSIRO framework to develop a system that reduces the negative impacts of MSW in

19 Bahir Dar city in a sustainable way. The research started by identifying the main driving forces

20 that lead to the generation of MSW. Then, states because of pressures and the consequent

21 impacts were investigated. Finally, the appropriate responses and outcomes obtained from the

22 responses were dealt with. Methods used to quantify GHG emissions, leachate, and

23 eutrophication potential were applied. According to the findings, the waste disposal site emits an 
24 estimated $46 \mathrm{Gg}$ of greenhouse gases per year in 2020.The eutrophication capacity of organic 25 waste generated in the city was $0.0594 \mathrm{Kg} \mathrm{N}$-equivalent or $59.4 \mathrm{~g}$ N-equivalent. The waste 26 also contains an average of $1,112 \mathrm{~mm}$ of leachate per day on an annual basis. The state of the

27 environment has an impact on human health and the ecosystem. Applying the circular economic system, knowledge transfer, and waste management fees are the main responses suggested to 29 decision and policy makers. The responses correspond with balanced economic, social and environmental situations. Outcomes were quantified in terms of organic fertilizer, income and

31 renewable energy (briquette) when the actions were taken.

32 Keywords: Sustainable management, Eutrophication potential, Greenhouse gas emission, 33 Municipal solid waste, Framework, Ethiopia

\section{Introduction}

Citizens and businesses in most of the world's cities consume a great deal of materials and 36 produce a great deal of waste (Makarichi et al., 2018). With rapid population and economic 37 growth and urbanization, solid waste output is increasing in urban areas around the world 38 (Farzadkia et al., 2020; Singh, 2019). According to a World Bank report (Franco et al., 2021; 39 Kaza et al., 2018) cities around the world generate roughly 2.01 billion tons of MSW per year, 40 and that number is projected to increase to 3.40 billion tons by 2050 . Clearly the solid waste 41 problem is a major concern for national and local authorities in many cities throughout 42 developing and developed countries (Inghels et al., 2016; Noufal et al., 2020). Especially in 43 developing countries, the common solid waste management system that they use is landfill 44 because it is relatively less costly to implement and operate than other options. However, 45 landfills are widely regarded as the least preferable municipal solid waste management system 46 due to its high contamination potential, including water and soil pollution due to the leachate 
47 seepage and greenhouse gases (GHGs) emissions resulting from the decomposition of

48 biodegradable waste (Adeleke et al., 2021; Wang et al., 2020), and the sequestration of 49 potentially reusable materials in lieu of recycling.

50 The negative impact of municipal solid waste due to its mismanagement in the cities covers from 51 local to global level. The release of odorous compounds from landfill has a very local (micro-) 52 impact as it affects the surrounding population. Discharge of pollutants into ground or surface 53 water due to landfilling can have an impact on the regional (meso-) scale, as eutrophication can 54 occur tens of kilometers away from disposal facilities unless fugitive leachate is collected and 55 properly treated. Emissions of greenhouse gases such as methane contribute to global warming, 56 which has an impact on the global population (macro impact) (Ellen et al., 2018; Matheus, 2018; 57 Mattos et al., 2020). The increasing demand for goods due to increased urbanization and 58 population is causing solid waste generation in Bahir Dar city to steadily increase. Currently, the 59 majority of solid waste produced in the city is dumped into open dumpsites without any 60 processing and uncontrolled emissions lead to negative impacts on soil, water and air 61 environment; these emissions are expected to continue in the future until MSW management 62 systems are improved.

63 Sustainable MSW management necessitates a multifaceted approach including a wide range of 64 stakeholders (Salem et al., 2020). The aim of the study was to apply the Driving force-Pressure65 State-Impact-Response-Outcome (DPSIRO) framework to study the potential impact of 66 municipal solid waste on air, soil and water quality and develop sustainable indicators to reduce 67 the impact. The DPSIRO framework is an extension of the DPSIR framework and it is a cycle 68 which relates to a particular human need and accompanying activities(Misganaw \& Teffera, 69 2021). The DPSIRO framework analysis describes that economic and social development, which 
70 are common driving force (D), exert pressure $(\mathrm{P})$ on the environment, and, as a result, the state

71 (S) of the environment such as depletion of natural resources and degradation of environmental

72 quality changes. These changes then have an impact (I) on the environment and human health.

73 Due to these impacts, society responds (R) to the driving force, the pressure, state or impact, and

74 then when society gives the response, the outcome $(\mathrm{O})$ shows the expected result at each

75 response of the impact.

\section{Methodology}

\subsection{Overview of study area}

The city of Bahir Dar was chosen for investigation of the possible negative impacts of MSW and the development of sustainable indicators to reduce the impacts using the DPSIRO framework. Bahir Dar is a town in Ethiopia's northwestern region, near the southern end of Lake Tana, at the headwaters of the Blue Nile River that then flows through Sudan and Egypt. The city is located at an elevation of approximately 1,820 meters above sea level, with geographic coordinates of $11^{0} 36^{\prime} \mathrm{N}$ and $37^{\circ} 25^{\prime} \mathrm{E}$. The establishment of Bahir Dar can be traced back to the fourteenth century, when Saint Kidane Miheret Church was built on the current site of Saint Giorgis Church (Biruk, 2017; Kassie, 2016; Tirusew et al., 2013).

The city evolved from a monastery administration site as well as a market place to a rapidly growing urban center. The Amhara National Regional State's administrative seat is now located there. The city is made up of five sub-cities that share a common geographical location and people's living habits. With the range of attractions on the nearby Lake Tana (Ethiopia's largest lake and popular for churches and monasteries on the lake's 37 islands), it has become one of the country's main tourist destinations. Currently, the city consists of more than 415,000 peoples. 
93 In this study, the DPSIRO framework has been applied to assess the impact of municipal solid

94 waste on soil, water and the air environment in Bahir Dar city. Figure 1 illustrates the cause and 95 effect relation between factors of the DPSIRO framework. During the time of study, initially the 96 driving forces which lead to the generation of municipal solid waste as pressure ware 97 determined. Second, the environmental change that results from pressure has been investigated. 98 The state change of the environment was quantified in terms of greenhouse gas emission, 99 eutrophication potential and leachate using mathematical models. Using an intergovernmental 100 panel on climate change (IPCC) model, the total amount of $\mathrm{CO}_{2}$ and $\mathrm{CH}_{4}$ emitted from Bahir Dar 101 city waste was estimated (Misganaw \& Teffera, 2021). According to IPCC guidelines, the 102 equation for measuring methane emissions from waste disposal sites was calculated using 103 equation1.

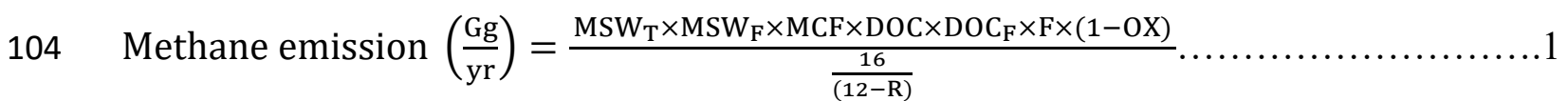

105 The abbreviations in the above equation represent, $\mathrm{MSW}_{\mathrm{T}}$ is total municipal solid waste 106 generated $(\mathrm{Gg} / \mathrm{yr}$.), MSW $\mathrm{F}$ represents the fraction of MSW disposed of in one or more solid 107 waste disposal sites, MCF is methane correction factor (fraction), DOC indicates degradable 108 organic carbon (fraction) $(\mathrm{kg} \mathrm{C} / \mathrm{kg} \mathrm{SW}), \mathrm{DOC}_{\mathrm{F}}$ illustrate fraction DOC dissimilated, $\mathrm{F}$ is fraction 109 of methane in waste dump gas, $16 / 12$ is the conversion of carbon to methane, $\mathrm{R}$ represents 110 recovered methane $(\mathrm{Gg} / \mathrm{yr}$.) and $\mathrm{OX}$ is oxidation factor (fraction-IPCC default is 0 ).

111 The approach assumes that all future methane emissions occur in the same year that the waste is

112 discarded. The method is straightforward, and calculating emissions needs only the input of a 113 small number of parameters, for which the IPCC guidelines provide default values in cases 114 where country or city-specific quantities and data are unavailable. The amount of methane gas 
115 released from the disposal site was estimated using the recommended degradable organic carbon 116 and decay rate value for waste disposal site.

117 The emissions of carbon dioxide from municipal solid waste disposal sites without gas collection 118 systems were calculated using $\mathrm{B}=A \times\left(\frac{1-F}{F}+O X\right) \times \frac{44}{16} \ldots \ldots \ldots \ldots \ldots \ldots 2$.

119 In equation 2 the variable $\mathrm{B}$ is $\mathrm{CO}_{2}$ emission $\left(\mathrm{Gg} / \mathrm{yr}\right.$.), A represents the quantity of $\mathrm{CH}_{4}$ 120 calculated from equation 1above $\left(\mathrm{Gg} \mathrm{CH}_{4} / \mathrm{yr}\right.$.), $\mathrm{F}$ is fraction by volume of $\mathrm{CH}_{4}$ in landfill gas, 121 generally assumed to be 0.5 , OX illustrates soil oxidation fraction, typically 0.1 (fraction) and the 122 numerical values 44 and 16 represent molecular weight of $\mathrm{CO}_{2}(\mathrm{~kg} / \mathrm{kg}$-mol) and molecular 123 weight of $\mathrm{CH}_{4}(\mathrm{~kg} / \mathrm{kg}-\mathrm{mol})$ respectively.

124 The eutrophication capacity of organic waste was calculated using equation 3, 4 and 5 after the 125 molecular formula of organic waste of Bahir Dar city determined.

$126 \quad \mathrm{EP}=\frac{V / M W}{V_{\text {ref }} / M W_{\text {ref }}} \ldots \ldots \ldots \ldots . . . . .3$,

$127 \quad \mathrm{~V}=P+\frac{N}{16}+\frac{T h O D}{138} \ldots \ldots . .4$ and

$128 \quad$ ThOD $=C+\frac{H-3 N}{4}+\frac{O}{2} \ldots \ldots \ldots . . . .5$.

129 The variables in the above three consecutive equations represent, EP is eutrophication potential, $130 \mathrm{P}$ indicates the number of phosphorus atoms in the molecule equals to 0 for all of our 131 compounds, $\mathrm{N}$ is the number of nitrogen atoms in the molecule, $\mathrm{O}$ illustrates the number of 132 oxygen atoms in the molecule, $\mathrm{C}$ is number of carbon atoms in the molecule, $\mathrm{H}$ represent number 133 of hydrogen atoms in the molecule, $\mathrm{V}$ ref is the $\mathrm{V}$ for phosphate anion, [PO4]3- and $\mathrm{V}$ ref equals 134 to $1, \mathrm{MW}$ ref indicate the MW for phosphate anion, [PO4] $3^{-}$and MW ref equals to $94.97 \mathrm{~g} / \mathrm{mol}$, $135 \mathrm{MW}$ is the MW of the compound and ThOD represent theoretical oxygen demand. The volume 136 of leachate resulting from municipal solid waste in Bahir Dar city were quantified by using the 
relation $\mathrm{L}=\mathrm{R}-\mathrm{E}_{\mathrm{a}} \ldots \ldots \ldots \ldots \ldots \ldots$........

138 The symbols in equation 6 represented as, $\mathrm{L}$ is the volume of leachate, $\mathrm{R}$ is the volume of rainfall 139 and $\mathrm{Ea}$ is the volume of real evapotranspiration (or simpler evaporation from the earth level).

140 Third, the impact that results from the change of soil, water and air quality was determined. Next

141 to the impact, the recommended responses and expected outcomes obtained from the possible 142 actions were determined. The responses and outcomes form a balanced relationship with 143 economic, social and environmental situations. Finally, the overall scenario of the DPSIRO 144 framework was conceptualized holistically by forming a balanced relation between economic, 145 social and environmental situation. [Figure 1]

\subsection{Data Collection, Data Source and Data Type}

147 All of the data needed to complete the DPSIRO framework analysis for this study was gathered 148 at the same time from both primary and secondary data sources. The five cases found in the city 149 were grouped into three major groups once the analysis was completed. The three major classes 150 were: inner, middle, and outer. A grouping technique based on population density, geographical 151 location, population settlement, and land use pattern was employed to make data gathering from 152 sample sites homogeneous. Data was randomly collected from the inner, middle, and outer 153 classrooms to make the data representative at the time.

154 There are around seventeen Keble's in the city's five Kefleketema. The core (inner) part includes 155 Keble 01, 02, 03, 04, 05, 06, and 12. 07, 08, 09, 10, 15, and 17 are the Keble's who belong to the 156 middle part. The remaining Keble numbers $11,13,14$, and 16 make up the outer group. This data 157 was obtained from the Bahir Dar city administration office, which falls under the Keble's level 158 category for 2016. From those categories, three Keble examples were chosen. Keble 05, Keble 15910 , and Keble 11 came from the center, middle, and peripheral, respectively. A total of 65, 96, 
160 and 62 households were chosen at random to be sampled. The total number of households taken

161 from both groups was 223.

162 The number of samples collected from sampling households was 33, 36, and 27 for the central, 163 middle, and inner regions, respectively, with a total weight of $646.215 \mathrm{~kg}$ from residential. The 164 events took place between January 18 and March 23, 2020. The data for this approach was 165 primarily gathered through solid waste characterization, focus group discussions, and face-to166 face interviews with responsible persons regarding solid waste management, industry 167 availability, and the population of Bahir Dar. Land observation was the other technique used. It 168 was carried out to determine the actual capacity of municipal solid waste collected in the area, as 169 well as their solid waste collection and sorting methods. Secondary data was gathered from both 170 existing and unpublished sources for the study.

171 3. Result and Discussion

172

\subsection{Deriving Force and Pressure}

173 Three main driving forces: natural population growth rate, economic growth and rapid 174 urbanization are led to generation of municipal solid waste in case of Bahir Dar city. With a 175 waste generation rate of $0.223 \mathrm{~kg}$ per capita per day, the municipal solid waste produced in Bahir 176 Dar city increased from 73.05 tons per day in 2007 to 148.13 tons per day in 2020 (Misganaw \& 177 Teffera, 2021). The average annual population growth rate of 6.6 percent is one of the key 178 factors that determines the shift in urban solid waste generation rate (Biruk, 2017; Tirusew et al., 179 2013). The study of municipal solid waste in Bahir Dar city revealed that as the city's population 180 grows, the amount of municipal solid waste generated grows as well. As shown in table 1 below, 181 solid waste production is rising in all waste generation sources. Depending on the result and from 
182 the total waste generated, only $58 \%$ was properly collected and disposed of and $86 \%$ of the total

183 waste generated is degradable (Asmare \& Alelign, 2019; Wegedie, 2018). [Table 1]

184 Based on the analysis of environmental sustainability of the DPSIRO model, the pressure of 185 municipal solid waste generation $(\mathrm{P})$ is initiated by the driving force of municipal solid waste 186 generation (D) and can block the action of the responsible community®. A large quantity of

187 solid waste is generated in residential areas. It covers around $55 \%$ of the total waste. Rapid 188 urbanization and technology used for production process are also considered as driving forces 189 leading to waste generation in the city. Production, consumption and land use for solid waste 190 disposal sites are pressures in addition to waste generation.

\subsection{State}

The pressure resulting from the driving force leads to changes in the state of environmental components, such as water, air and soil quality. This environmental degradation creates an

194 elevated threat to economic growth and development (Chapagain et al., 2020). Change in 195 environmental quality is a combination of physical, chemical and biological conditions.

\subsubsection{Greenhouse Gas Emission (GHGs)}

197 Air pollution is one of the world's most important challenges, with long- and short-term health 198 consequences in countries of all socioeconomic levels (Luiz et al., 2020; Maroosi et al., 2019).

199 GHGs, such as $\mathrm{CH}_{4}$ and $\mathrm{CO}_{2}$, are produced from the aerobic and anaerobic biodegradation of 200 municipal solid waste (Zhang et al., 2019). The amount of $\mathrm{CH}_{4}$ and $\mathrm{CO}_{2}$ emitted from Bahir Dar 201 city dump site was determined using the IPCC model. In this paper, municipal solid waste equals 202 the amount of urban waste transported to the disposal site, then the $\mathrm{MSW}_{\mathrm{F}}$ is equal to $58 \%$ and 203 the remaining $42 \%$ is assumed to be lost due to recycling, waste burning at source, waste thrown 
204 in to the drains and waste not reaching in to dump site due to insufficient solid waste 205 management system. This insufficient management increases the transmission of diseases, causes 206 contamination of surface and ground water, greenhouse gas emissions, and ecosystem damage.

207 The total GHG emissions from dumpsite are calculated as the sum of the $\mathrm{CO}_{2}$ emissions and the $208 \mathrm{CH}_{4}$ emissions (converted to $\mathrm{CO}_{2 \mathrm{eq}}$ ) (Misganaw \& Teffera, 2021). The result obtained by using 209 this relation was $23.112 \mathrm{Gg}$ in 2007 and reached $46.873 \mathrm{Gg}$ in 2020 . As the result indicated in

210 figure 2 the emission of greenhouse gases is increasing from time to time from 2007 to 2020.

$211 \quad$ [Figure 2]

$212 \quad$ 3.2.2. Eutrophication Potential

213 Another state condition that occurs in a water body when the composition of organic waste rises 214 during the generation of municipal solid waste is eutrophication. The chemical formula of 215 organic waste produced in Bahir Dar city was determined to calculate the EP (excessive 216 biological activity of organisms due to over-nitrification) of municipal solid waste generated in 217 the area. The organic waste generated in the city with percentage coverage was indicated in table 218 2. [Table 2]

219 Table 3 indicates the percentage chemical composition of organic wastes in terms of carbon, 220 hydrogen, oxygen, and nitrogen. The weight of carbon $(\mathrm{C})$, hydrogen $(\mathrm{H})$, oxygen $(\mathrm{O})$, and 221 nitrogen $(\mathrm{N})$ for each portion of organic waste was determined using the data in table 3 . The aim 222 of determining the weight of elements found in organic waste was to determine the waste's 223 chemical molecular formula in terms of carbon, hydrogen, oxygen, and nitrogen to determine 224 eutrophication potential. [Table 3] 
225 The chemical composition of organic wastes was determined based on the composition in the

226 table above. The total percentage composition calculated in the organic part of municipal solid

227 waste of Bahir Dar city is indicated in table 4. [Table 4]

228 The eutrophication potential (EP) can be calculated for any compound that contains only C, H, N

229 and O. In order to determine the eutrophication potential of organic waste generated in Bahir Dar

230 city, obtaining the molecular formula of the organic waste is required. Then the molecular

231 formula of the waste can be obtained by dividing each component by its molecular weight by

232 excluding sulfur and ash. To obtain the general chemical formula that is present in organic

233 municipal solid waste of Bahir Dar city, use the lowest represented element nitrogen as the base.

234 After taking nitrogen as the base, then dividing each value of the element by the number of

235 moles of nitrogen and the result is indicated in table 5. [Table 5]

236 As indicated in table 5, the organic waste produced in the city has the chemical formula

$237 \mathrm{C}_{24} \mathrm{H}_{36} \mathrm{O}_{13} \mathrm{~N}$. The calculated value of ThOD and $\mathrm{V}$ were 38.75 and 0.343 respectively by using

238 the molecular formula of organic waste of the city and mathematical equations in the material

239 and method part. The eutrophication potential of organic waste produced in Bahir Dar city was

$240 \quad 0.0594 \mathrm{Kg} \mathrm{N}$-equivalent or $59.4 \mathrm{~g} \mathrm{~N}$-equivalent.

\section{$241 \quad 3.2 .3$. Leachate}

242 Like greenhouse gas emission and eutrophication, leachate is another factor which changes the

243 state of a given environment. A number of factors influence the proportion of leachate generated,

244 including waste characteristics, structure, and compressed congestion; weather conditions, 245 average annual temperature, cell size, and gradual processing of the disposal region; and ground 246 water impacts. 
247 Generally, leachate quantity is patterned or specified through an easy water equilibrium method,

248 considering the amount of water reaching the landfill and the level of water departing from the

249 landfill (that is water used in biochemical processes and evaporation). The average annual

250 evapotranspiration of Bahir Dar city is $307 \mathrm{~mm}$ per day and the average annual temperature and

251 rainfall is $19.6^{\circ} \mathrm{C}$ and $1419 \mathrm{~mm}$ per day respectively (source: national metrology agency). Then

252 the average amount of leachate that is found from municipal solid waste of Bahir Dar became

$2531,112 \mathrm{~mm}$ per day.

\subsection{Impact}

255 In the DPSIRO framework, impacts are expressed in terms of the effect of change in the quality

256 of the environment (soil, air and water) on social and ecological systems. Ecosystem and human

257 welfare effects are both included in the impacts, however the former is focused on ecosystem

258 problems such as reducing water, soil and air quality (Cooper, 2013). Indicators in the impact

259 component of the DPSIRO framework are used to measure the change in state of air, soil and

260 water due to the pressure and the driving force caused by the state of air, soil and water

261 environment change. As indicated in figure 2, the emission of greenhouse gases increased from

262 23.112Gg to 46.873Gg in the years between 2007 and 2020 (Misganaw \& Teffera, 2021). By

263 trapping heat, this rise contributes to climate change, as well as respiratory problems caused by

264 smog and pollution. The increment of GHG emissions induces genetic damage in animals, plants

265 and bacteria in addition to human health impact (Mussury \& Rocha, 2020). Other implications of

266 climate change produced by greenhouse gases include extreme weather, food supply shortages,

267 and increasing wildfires.

268 The eutrophication potential of municipal solid waste in the city is high and this leads to toxic

269 poisons for human health that can be produced by harmful algal bloom species. Algal toxins can 
270 build in shellfish and, more broadly, seafood, reaching harmful levels for human and animal

271 health. Shellfish poisoning can result in paralysis, neurotoxicity, or diarrhea. Eutrophication has

272 high ecological impact in addition to human health impact. Lake Tana water, which is the largest

273 lake in Ethiopia, is found in Bahir Dar city and has high fish products for the community.

274 Increased turbidity or reduced light penetrations into the lower depths of the water column are

275 both caused by phytoplankton development. This can stifle the growth of submerged aquatic 276 plants in lakes, affecting species that rely on them.

277 Leachate also leads to various human health impacts like greenhouse gas emission and 278 eutrophication. Sweating, bleeding, and stomach ailments can all be induced by drinking 279 contaminated leachate water, according to medical literature, as can blood disorders, congenital 280 defects, and even cancer. Solid wastes generate organic pollutants and taken by agricultural 281 plants and their accumulation in edible parts cause serious health problems to animals and 282 humans (Parlavecchia \& Loffredo, 2020).

\subsection{Responses}

284 There are various groups of responses in order to protect the resulting impact by municipal solid 285 waste generation on water, air and soil environment. This response is taken by society to 286 environmental situation and an initiative intended in order to reduce at least one impact (Cooper, 287 2013; Neves et al., 2008). Accordingly, the responses that given during the time of study are: 288 sustainable with environment (i.e. friendly with nature in current time and future), 289 technologically feasible with adequate method and equipment, economically feasible, wanted by 290 the society live in the city, legally much with national as well as international legislations and 291 also administratively attainable. The responsible parties either individuals or groups present in 292 Bahir Dar could consider the following responses: shifting the policy from a linear to a circular 
293 economy (i.e. applied the wastes produced from one sector to as an input for another one). There

294 are several studies that can be used as inputs to convert Bahir Dar's policy from a linear to a 295 circular economy system (Asmare \& Alelign, 2019; Biruk, 2017). According to (Asmare \& 296 Alelign, 2019), more than 74 percent of Bahir Dar City's municipal solid waste can be used to 297 make briquettes, and over 86 percent of the waste can be composted into organic fertilizer.

298 The application of user fees for waste management services is the next possible action. Because 299 it imposes fees on waste generators, this reaction is a very essential policy for reducing the city's 300 garbage creation from various sources. The goal of imposing trash charges is to reduce waste 301 generation both in terms of quantity and risk, as well as to improve waste recovery (Michel et al., 302 2018; Sanjeevi \& Shahabudeen, 2015). Transportation and garbage treatment fees are included in 303 the prices, which should be lower for separated waste than for mixed waste. The purpose of the 304 trash tax is to promote garbage recovery and reduce waste on the land (Misganaw \& Teffera, 305 2021). Create awareness for community regarding with reducing, reusing and recycling should 306 be increased; suitable policies and frameworks regarding to solid waste management should 307 implement and monitor properly; built the ability of municipality in terms of economic, 308 personnel and technical aspects and transfer information for community regarding to health, 309 socio-economic and other harmful impacts of improper solid waste management of the city are 310 important responses to reduce the generation and impact of waste.

312 The reaction to the DPSIRO model resulted in high efficiency in research to assist decision 313 makers in developing and executing policies in favor of the city's municipal solid waste 314 management system (Misganaw \& Teffera, 2021). The strategic actions taken by responsible 315 parties at various level of DPSIRO framework (driver, pressure, state and impact) leads to 
316 significant outputs with related to social, environmental and economic sustainability. The

317 possible responses dealt in this research leads to various outcomes. From those out comes, the

318 three basic states that identified in soil, water and air (leachate, eutrophication and greenhouse

319 gas emission) can be reduced due to waste quantity reduction in waste disposal site. Currently

320 the waste disposal site of Bahir Dar city consumes around 22 hectare (Asmare \& Alelign, 2019).

321 So, implementation of 3R policy in municipal solid waste management of Bahir Dar city results

322 in creating of lands for construction, farming and other purposes from waste disposal site. The

323 impacts resulting from inorganic fertilizer also can be reduced by substituting it by organic

324 fertilizer (compost) using compostable wastes as raw material. The city now produces 148.12

325 tons of municipal solid trash each day. With a waste density of $162.3 \mathrm{~kg} / \mathrm{m}^{3}$, the annual volume

326 of waste is $333,291.6 \mathrm{~m}^{3}$ per year. A maximum of $0.6 \mathrm{~m}^{3}$ of solid waste is required for the

327 creation of one quintal $(100 \mathrm{~kg})$ of compost, according to Dream Light PLC's expertise. This

328 indicates that 47,772 ton of compost can be made from 86 percent of biodegradable garbage per

329 year. The average total amount of money produced per year, according to this product, is around

330 1,313,724 Birr (Misganaw \& Teffera, 2021).

331 In addition to the financial benefits, the environmental consequences of municipal solid waste

332 mishandling are mitigated. Knowledge transmission regarding municipal solid waste

333 management and the use of waste taxes and levies in society in the context of a circular economy

334 raises public awareness about trash income production and protects people's economy,

335 environment, and health. Figure 3 uses the DPSIRO framework to summarize the result of better

336 knowledge of the overarching concept of the research. [Figure 3]

337 4. Conclusion on Research Findings 
338 The DPSIRO framework indicated the overall scenario of impact of municipal solid waste on air,

339 water and soil impacts. The generation of municipal solid waste in Bahir Dar city is increasing

340 from time to time due to population growth and economic transformation as a driving force. This

341 leads to a change in the quality of the given environment by mismanagement of municipal solid

342 waste. Currently, a large portion of the waste that is generated in Bahir Dar city is disposed

343 directly into an open dumpsite without any sorting activity. The amount of greenhouse estimated

344 from waste disposal sites reaches $46 \mathrm{Gg}$ per year in terms of carbon dioxide equivalent. Most of

345 the waste generated in the city is organic with the molecular formula $\mathrm{C}_{24} \mathrm{H}_{36} \mathrm{O}_{13} \mathrm{~N}$. This waste

346 increases the eutrophication in the water body with the potential of $0.0594 \mathrm{Kg} \mathrm{N}$-equivalent. The

347 average amount of leachate that is found from municipal solid waste of Bahir Dar is 1,112mm

348 per day with an average annual temperature and rainfall is $19.6^{\circ} \mathrm{C}$ and $1419 \mathrm{~mm}$ per day

349 respectively.

350 These greenhouse gas emissions, eutrophication potential and leachate are considered under state 351 factors of the DPSIRO framework. The waste generated in the city poses various impacts on

352 human health and wildlife. The scenario of the response indicated that Bahir Dar city should start

353 to implement reduction, reuse and recycling solid management options in order to reduce

354 potential environmental and human health impacts with economic benefits. The waste 355 composition is also used as an input in order to implement those management options. As the 356 output obtained indicates, if Bahir Dar city implements reduction, reuse and recycling, it is 357 possible to produce 47,772 ton of compost from 86 percent of biodegradable garbage per year.

358 The average total amount of money produced per year, according to this product also around $3591,313,724$ Birr. The responses identified in this study leads to environmental, social and 
360 economic balance. For more investigation, quantification of the other impacts associated with

361 municipal solid waste is recommended.

362 Declaration of interests

363 The authors declare that they have no known competing financial interests or personal 364 relationships that could have appeared to influence the work reported in this paper.

\section{Data Availability Statement}

366 The datasets generated during and/or analyzed during the current study are available from the

367 corresponding author on reasonable request.

368 Author's contribution

369 Awoke Misganaw: Conceptualization, Methodology, and Software, Data curation, Writing370 Original draft preparation: Visualization, Investigation, Supervision, and Validation.

371 Banchamlak Akenaw: Methodology, Data curation, Visualization, Writing- Reviewing and 372 Editing.

\section{Funding Information}

374 Funding information is not applicable / No funding was received

\section{References}

376 Adeleke, O., Akinlabi, S. A., Jen, T. C., \& Dunmade, I. (2021). Application of artificial neural 377 networks for predicting the physical composition of municipal solid waste: An assessment 378 of the impact of seasonal variation. Waste Management and Research, 39(8), 1058-1068. 379 https://doi.org/10.1177/0734242X21991642

380 Asmare, M., \& Alelign, B. (2019). Bahir Dar City Municipal Solid Waste Potential Assessment 381 for Clean Energy. American Journal of Energy Engineering, 7(1), 28-38. $382 \quad$ https://doi.org/10.11648/j.ajee.20190701.14 
Biruk, A. F. (2017). Waste management in the case of Bahir Dar City near Lake Tana shore in Northwestern Ethiopia: A review. African Journal of Environmental Science and Technology, 11(August), 393-412. https://doi.org/10.5897/AJEST2017.2340

Chapagain, S. K., Mohan, G., \& Fukushi, K. (2020). An Extended Input - Output Model to Analyze Links Between Manufacturing and Water Pollution in Nepal. Water Air Soil Pollut, 1-11. https://doi.org/https://doi.org/10.1007/s11270-020-04940-0

Cooper, P. (2013). Socio-ecological accounting: DPSWR, a modified DPSIR framework, and its application to marine ecosystems. Ecological Economics, 94, 106-115. https://doi.org/10.1016/j.ecolecon.2013.07.010

Ellen, Sue, Taelman, Ellen, S., Tonini, Davide, Wandl, \& Alexander. (2018). A Holistic Sustainability Framework for Waste Management in European Cities: Concept Development. Sustainability. https://doi.org/10.3390/su10072184

Farzadkia, M., Jorfi, S., Nikzad, M., \& Nazari, S. (2020). Evaluation of industrial wastes management practices: Case study of the Savojbolagh industrial zone, Iran. Waste Management and Research, 38(1), 44-58. https://doi.org/10.1177/0734242X19865777

Franco, D. G. de B., Steiner, M. T. A., \& Assef, F. M. (2021). Optimization in waste landfilling partitioning in Paraná State, Brazil. Journal of Cleaner Production, 283. https://doi.org/10.1016/j.jclepro.2020.125353

Inghels, Dirk, Dullaert, Wout, Bloemhof, \& Jacqueline. (2016). A model for improving sustainable green waste recovery. "Resources, Conservation \& Recycling," 110, 61-73. https://doi.org/10.1016/j.resconrec.2016.03.013

Kassie, K. E. (2016). The problem of solid waste management and people awareness on appropriate solid waste disposal in Bahir Dar City: Amhara region, Ethiopia. ISABB 
Journal of Health and Environmental Sciences, 3(1), 1-8. https://doi.org/10.5897/ISAAB-

407

408

409

410

411

412

413

414

415

416

417

418

419

420

421

422

423

424

425

426

427

428

JHE2016.0026

Kaza, S., Yao, L., Bhada-tata, P., \& Woerden, F. Van. (2018). What a waste 2.0: A Global Snapshot of Solid Waste Management to 2050. World Bank. https://doi.org/doi:10.1596/978-1-4648

Luiz, M., Rogério, P., Patricia, V., Kawase, R., Tribess, A., \& Morawska, L. (2020). Impact of Filtration Conditions on Air Quality in an Operating Room. International Journal of Environmental Research, 14(6), 685-692. https://doi.org/10.1007/s41742-020-00286-X

Makarichi, L., Techato, K., \& Jutidamrongphan, W. (2018). Material fl ow analysis as a support tool for multi-criteria analysis in solid waste management decision-making. Resources, Conservation \& Recycling, 139(March), $351-365$. https://doi.org/10.1016/j.resconrec.2018.07.024

Maroosi, M., Mesdaghinia, A., Alimohammadi, M., Naddafi, K., Mahvi, A. H., \& Nabizadeh Nodehi, R. (2019). Developing environmental health indicators [EHIs] for Iran based on the causal effect model. Journal of Environmental Health Science and Engineering, 17(1), 273279. https://doi.org/10.1007/s40201-019-00346-1

Matheus, D. R. (2018). The impact of socioeconomic factors on municipal solid waste generation in São. Waste Management \& Research. https://doi.org/10.1177/0734242X17744039

Mattos, R., Daniel, F., \& Stolte, B. (2020). A municipal solid waste indicator for environmental impact: Assessment and identi fi cation of best management practices. Journal of Cleaner Production, 242, 118433. https://doi.org/10.1016/j.jclepro.2019.118433

Michel, R., de Bilbao, E., \& Poirier, J. (2018). Recycling Bauxite Waste for the Mineral 
Industry: Phase Transformations and Microstructure During Sintering. Waste and Biomass Valorization, 9(7), 1261-1271. https://doi.org/10.1007/s12649-016-9775-y

Misganaw, A., \& Teffera, B. (2021). Development of DPSIRO framework indicators for municipal solid waste management: a case of Bahir Dar city, Ethiopia. Journal of Material Cycles and Waste Management. https://doi.org/10.1007/s10163-021-01266-9

Mussury, R. M., \& Rocha, A. do N. (2020). Green Areas in an Urban Environment Minimize the Mutagenic Effects of Polluting Gases. Water Air Soil Pollut. https://doi.org/https://doi.org/10.1007/s11270-020-04929-9

Neves, R., Baretta, J., \& Mateus, M. (2008). The DPSIR framework applied to the integrated management of coastal areas. Perspectives on Integrated Coastal Zone Management in South America, October. https://doi.org/10.13140/2.1.3841.6960

Noufal, M., Yuanyuan, L., Maalla, Z., \& Adipah, S. (2020). Determinants of household solid waste generation and composition in Homs city, Syria. Journal of Environmental and Public Health, 2020. https://doi.org/10.1155/2020/7460356

Parlavecchia, M., \& Loffredo, E. (2020). Soil Amendment with Biochar , Hydrochar and Compost Mitigates the Accumulation of Emerging Pollutants in Rocket Salad Plants. Water, Air, \& Soil Pollution. https://doi.org/10.1007/s11270-020-04915-1

Salem, Mohammed, Raab, Katharina, Wagner, \& Ralf. (2020). Solid waste management: The disposal behavior of poor people living in Gaza Strip refugee camps. Resources, $\begin{array}{llll}\text { Conservation } \quad \& \quad \text { Recycling, } & \text { 153(October } & 2019), & 104550 .\end{array}$ https://doi.org/10.1016/j.resconrec.2019.104550

Sanjeevi, V., \& Shahabudeen, P. (2015). Development of performance indicators for municipal solid waste management (PIMS): A review. Waste Management and Research, 33(12), 
453 Singh, A. (2019). Solid waste management through the applications of mathematical models Solid Waste in Urban Areas. Resources, Conservation \& Recycling, 151(September), 104503. https://doi.org/10.1016/j.resconrec.2019.104503

456

457

458

459

460

461

462

463

464

465

466

467

468

469
Tirusew, Ayisheshim, Ebistu, Minale, Sewnet, \& Amare. (2013). Solid waste dumping site suitability analysis using geographic information system ( GIS ) and remote sensing for Bahir Dar Town, North Western Ethiopia. African Journal of Environmental Science and Technology, 7(November), 976-989. https://doi.org/10.5897/AJEST2013.1589

Wang, D., Tang, Y., Long, G., Higgitt, D., He, J., \& Robinson, D. (2020). Future improvements on performance of an EU landfill directive driven municipal solid waste management for a city in England. Waste Management, $\quad$ 102, 452-463. https://doi.org/10.1016/j.wasman.2019.11.009

Wegedie, K. T. (2018). Households solid waste generation and management behavior in case of Bahir Dar City, Amhara National Regional State, Ethiopia. Cogent Environmental Science, 4(1), 1-18. https://doi.org/10.1080/23311843.2018.1471025

Zhang, C., Xu, T., Feng, H., \& Chen, S. (2019). Greenhouse Gas Emissions from Landfills : A Review and Bibliometric Analysis. Sustainability, 16 April, 1-15. 
Figures

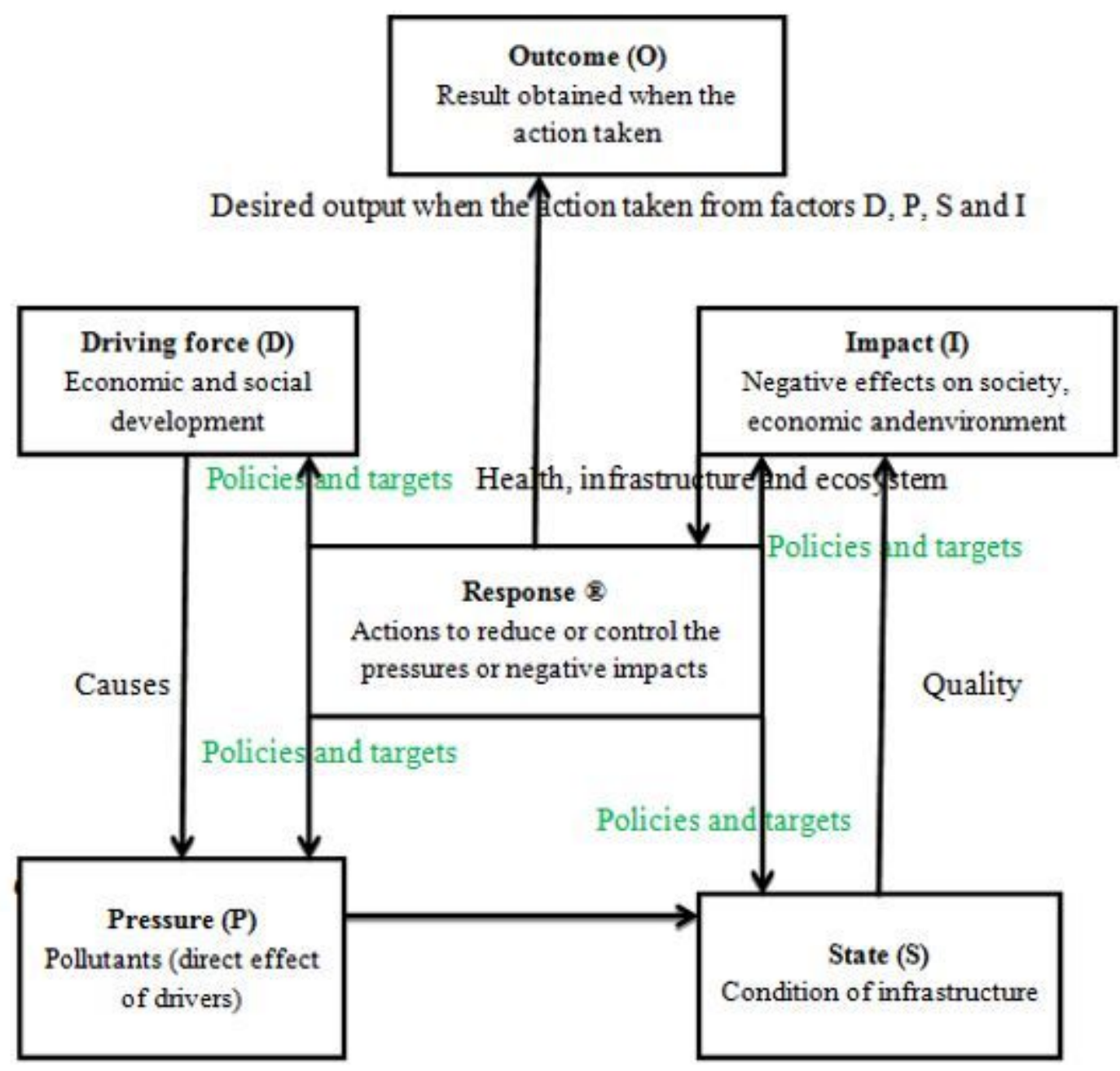

Figure 1

The DPSIRO conceptual framework developed by authors 


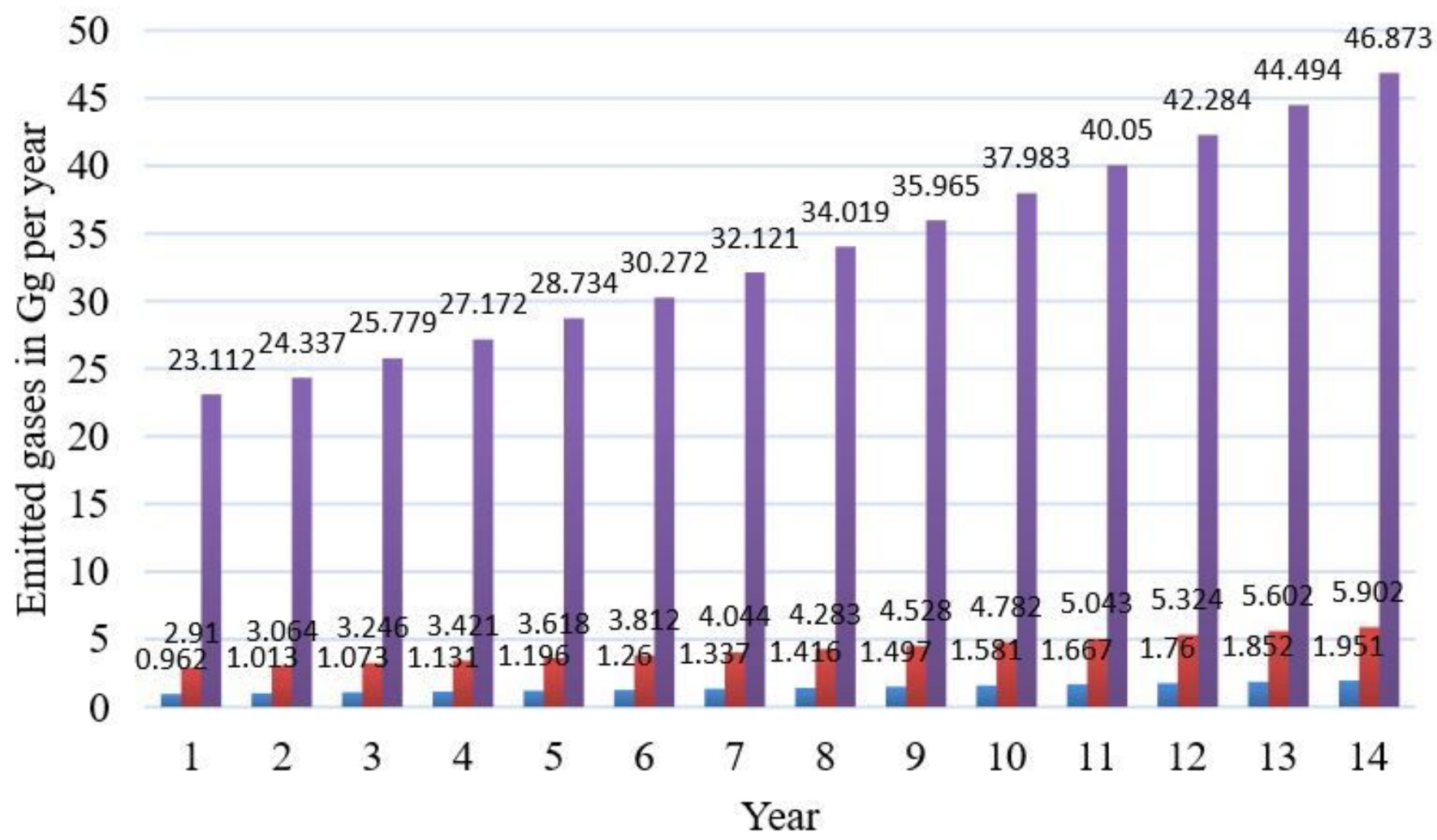

घCH4 emission $=\mathrm{CO} 2$ emission $\quad$ Total GHGs emission from dumpsite

Figure 2

Net annual GHGs emission (Gg per year) from 2007 to 2020 


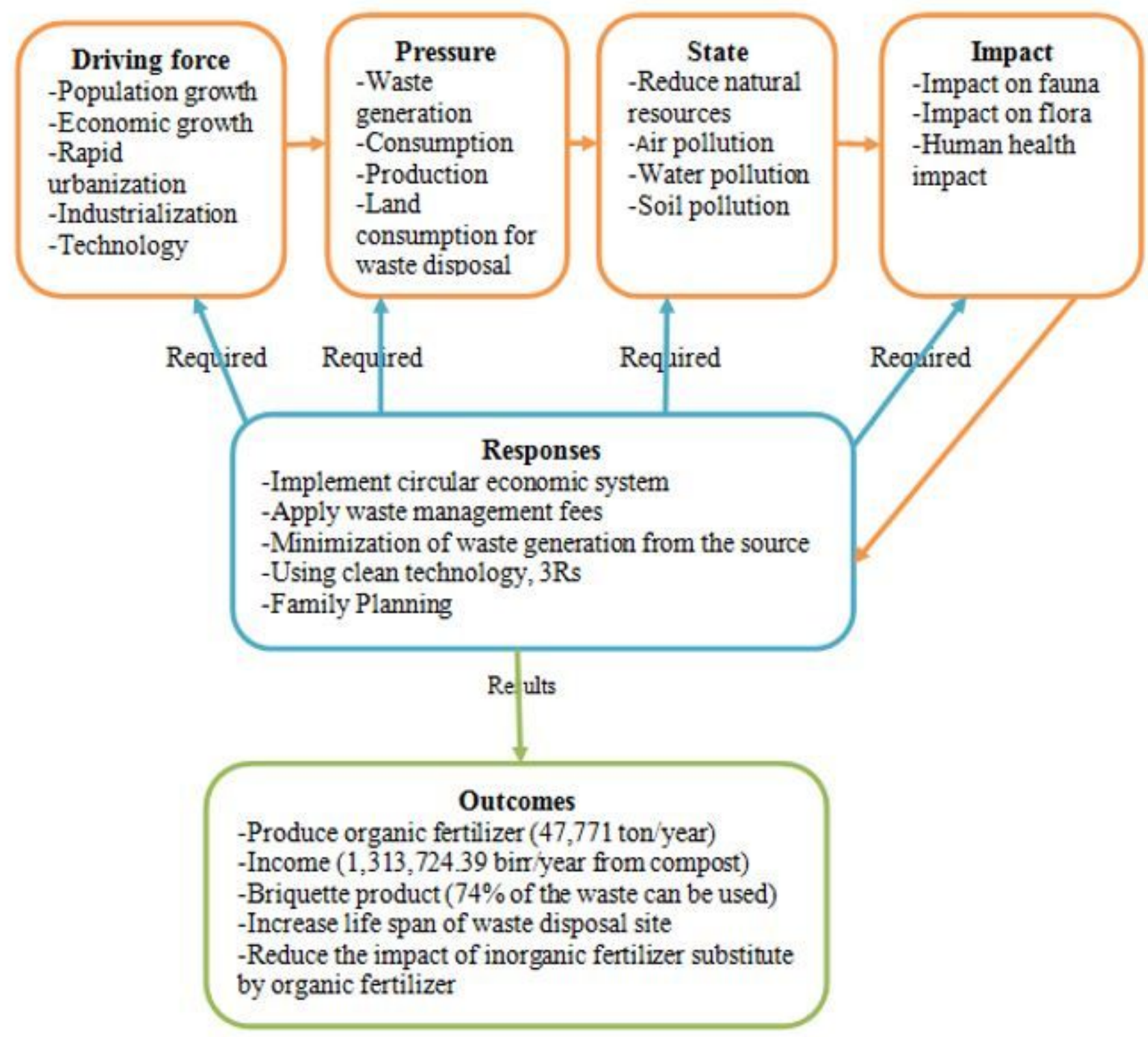

Figure 3

Scenario of DPSIRO framework for municipal solid waste management system of Bahir Dar city 